\title{
OBSERVABILITY THEORY APPLICATION TO AC INDUCTION MACHINE SENSORLESS CONTROL
}

\author{
VACLAVEK, P. \& BLAHA, P.
}

Abstract: AC induction motors become very popular for motion control applications due to their simple and reliable construction. There are applications in which speed sensors should be omitted, to achieve cost reduction. In such a situation, we have to solve the task of state reconstruction only from voltage and currents measurements design so called sensorless control algorithm. In the current paper, we present a simplified AC induction machine model suitable for speed observer design together with its observability analysis. Conditions of speed and rotor resistance observability are defined.

Key words: induction machine, observability analysis, sensorless control, rotor resistance
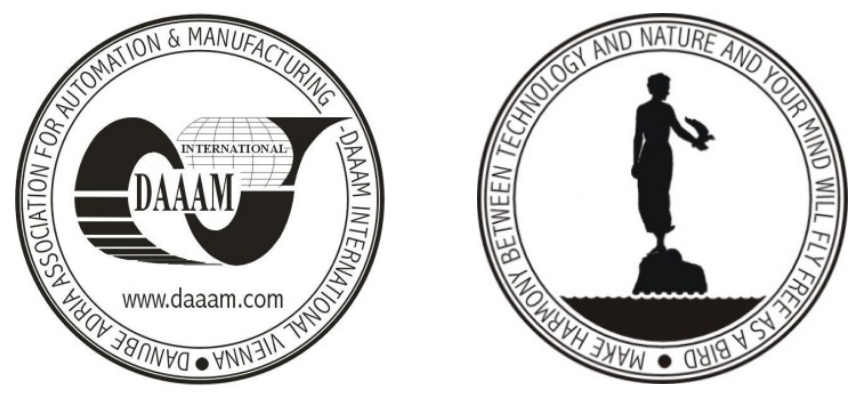

Authors' data: Dr. Vaclavek, P[avel]; Dr. Blaha, P[etr], Brno University of Technology, FEKT UAMT, 61200, Brno, CZ, vaclavek@feec.vutbr.cz, blahap@feec.vutbr.cz

This Publication has to be referred as: Vaclavek, P[avel] \& Blaha, P[etr] (2008). Observability Theory Application to AC Induction Machine Sensorless Control, Chapter 74 in DAAAM International Scientific Book 2008, pp. 903-918, B. Katalinic (Ed.), Published by DAAAM International, ISBN 978-3-901509-66-7, ISSN 17269687, Vienna, Austria

DOI: 10.2507/daaam.scibook.2008.74 